\title{
RELIABILITY OF VERNIER CALIPER MEASUREMENTS OF THE THORACIC PEDICLE TRANSVERSE DIAMETER
}

\section{E.N. Muteti , M.G.Y. ElBadawi}

Correspondence to: Dr Elijah Muteti, P. O. Box 1998-30100, Eldoret, Kenya. Email: enmuteti@gmail.com

\begin{abstract}
The thoracic pedicle is generally cylindrical with various indentations on its surface that may introduce an error in measurements, thus making the measurements unreliable. One hundred and eighty thoracic pedicle diameter measurements were carried out in five cadaveric human thoracic spine specimens, using a Vernier caliper. Coefficient of variation (CV) was used to evaluate the variation in measurements within and between pedicles. Linear regression model was used to evaluate the relationship between the variation in measurements and the average diameter of the bone per cadaver. The largest standard deviations in the five specimens were found at T2, T3, T6 and T12 levels. The least standard deviations were found at T1, T7, T9, T10 and T11. Four specimens demonstrated a negative linear relationship between the coefficient of variation and the average transverse diameter of the pedicle. This relationship was significant $(p<0.05)$ in two specimens. Vernier caliper measurements tend to be less reliable as the thoracic pedicle transverse diameter decreases. Caution is required when measuring the thoracic pedicle transverse diameter in the narrower mid-thoracic area of the spine with Vernier calipers.
\end{abstract}

Keywords: reliability, thoracic pedicle morphometry

\section{INTRODUCTION}

The outer transverse diameter of the thoracic pedicle has been documented in various studies (Berry et al, 1987; Zindrick et al, 1987; Krag et al, 1988; Hou et al, 1993; Heller et al, 1999; Datir and Mitra 2004; Christodoulou et al, 2005; Liau et al, 2006; Choi et al, 2009; Kim et al, 2009; Kretzer et al, 2011; Roop et al, 2011; Bunmaprasert et al, 2014; Yu et al, 2014; Yu et al, 2015). This measurement can be done at the anterior end, at the middle and at the posterior end of the pedicle (Gangadhara, 2013). The most frequently measured site is the isthmus of the pediclebecause it determines the size of pedicle screw that can be used in spine fixation surgery (McLain et al, 2002). Measurements can be performed on cadaveric thoracic vertebral specimens using Vernier calipers;

\section{METHODOLOGY}

One hundred individual cadaveric thoracic spine specimens of Kenyan descent were available at the National Museum of Kenya for this study. It was noted that it took 5minutes to carry out the measurements in one thoracic spine specimen. Since each pedicle needed to be measured at least twice, three repeat measurements were chosen. That would require 15 minutes per thoracic spine specimen. Five thoracic spine specimens would and on axial CT scan images axial using the inbuilt software measurement ruler.

The authors of this article noticed that the described shape of the thoracic pedicle is generally cylindrical with irregularity of the surface, which was more marked in some vertebrae more than others (Scoles et al, 1988). This may interfere with the reliability of the measurements. Consequently, this study sought to determine the reliability of measurement of the outer transverse diameter at the isthmus of the thoracic pedicle using a Vernier caliper by evaluating the differences in repeated transverse diameter measures of different thoracic spine pedicle specimens. 
three times. The specimens were numbered from 1 to 5 . The order of individual thoracic spine specimen measurement was determined randomly by use of a box from which the numbers 1 to 5 were drawn by the co-investigator. The first author then sequentially measured the right pedicle of the first thoracic vertebrae down to the twelfth thoracic vertebra, using the same Vernier caliper. The measurements were recorded to the nearest $0.1 \mathrm{~mm}$. The same measurements were done for the other specimens until all five were complete. The procedure of randomization was done again and the specimens re-measured.

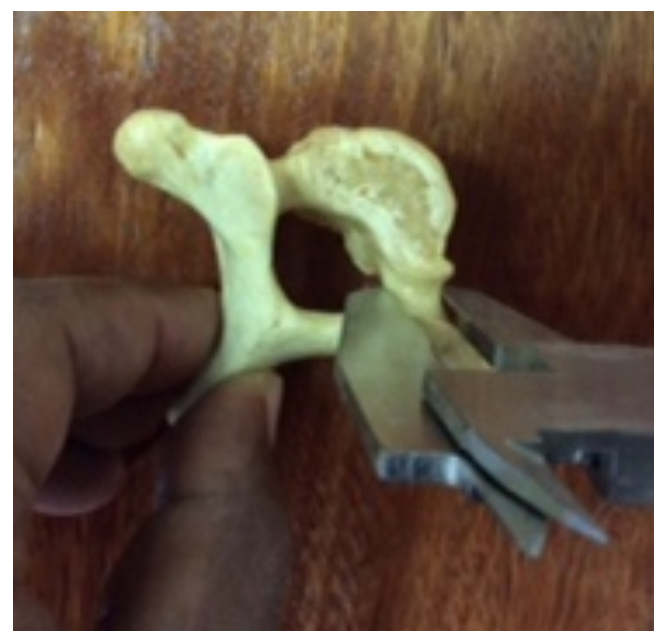

Figure 1: Anterior pedicle measurement technique
Analysis of coefficient of variation (CV) was used as criterion to measure the reliability of the multiple/repeat measurements. The randomness in the variation of the CV was graphically assessed by plotting against the average pedicle diameter and linear regression model was fitted to evaluate the relationship between the variation in measurements and the transverse diameter of the thoracic. Significance of the model was used to ascertain the impact of the measurement protocol on the variation of the different measure obtained.

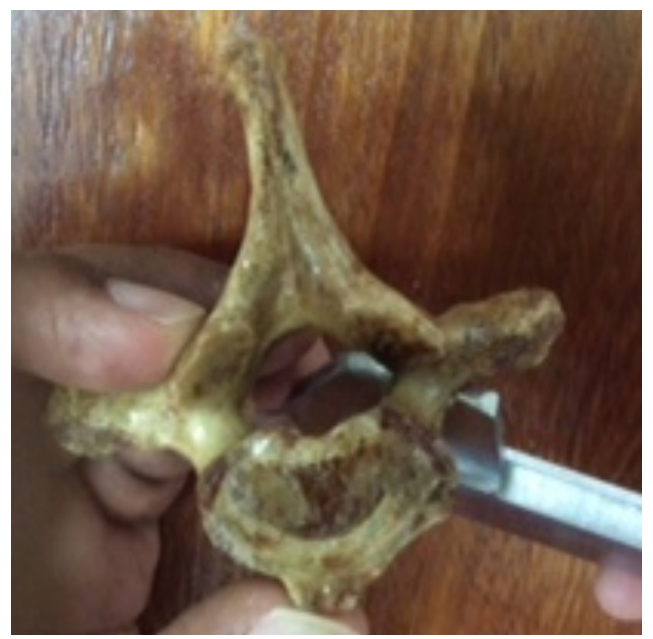

Figure 2: Posterior pedicle measurement technique

\section{RESULTS}

The narrowest pedicles in the thoracic spine were found at T4, T5 or T6; while the widest were found atT10, T11 or T12. Table 1 below shows the average diameters and standard deviations (SD) calculated from the three measurements for each pedicle from the five cadavers. Generally, the SD was higher for narrower pedicles compared to wider pedicles.

For measurements to be considered reliable, the errors should follow a normal distribution with a mean zero and a defined standard deviation and should be independent of the covariates. Since there's no defined standard deviation for the population of bones in this study, reliability of the measurements was evaluated by checking if the variation in measurements was due to chance. Figure 3 below demonstrates a linear relationship (negative) between the variations (CV) in the cadaver bone measurements and the average diameter of the thoracic pedicle in specimens 1 to 4 . Therefore, the magnitude of error in measurements obtained decreased with increase in the average diameter of the bone being measured. 
Figure 3: Distribution of measurement errors (CV) versus average pedicle diameter

\section{Coefficient of variation versus average diameter of thoracic pedicle}

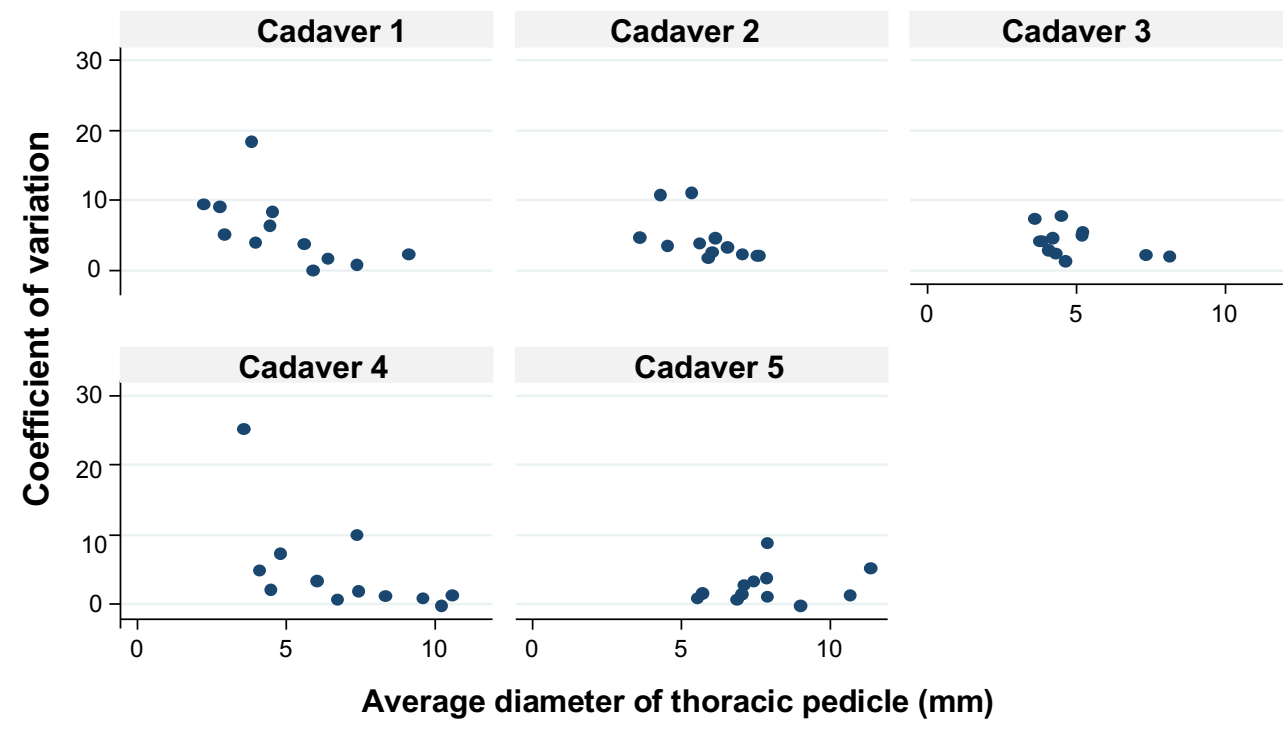

In figure 4 below, the distribution of the coefficient of variation (CV) was more spread in spine specimens 1 and 4 compared to spine specimens 2 , 3 and 5 . Outliers were noted in spine specimen 2,4 and 5 .

A linear regression model was fit to evaluate the relationship between the variation in measurements and the transverse diameter of the thoracic pedicle measured at the isthmus (Table 2). The model showed that the variations in measurements were significantly associated with the average diameter of the bones for cadavers 1 and 4 . This significant association between the variation of measurement errors and average diameter of cadavers 1 and 4 can be due to the extreme $\mathrm{CV}$ values observed in Figure 3.

Figure 4: Distribution of measurement errors (CV) by cadaver

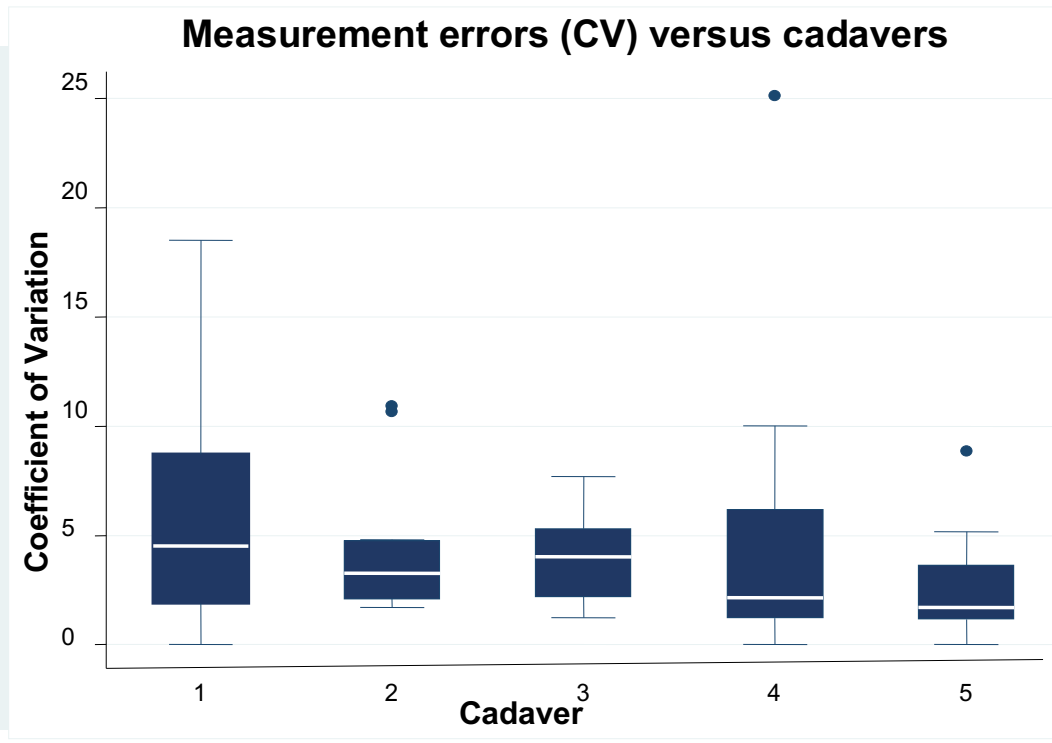


Anatomy Journal of Africa. 2018. Vol 7 (2): 1232 - 1237.

Table 1: Summary statistics for thoracic pedicle transverse diameter measurements

\begin{tabular}{|r|l|l|l|l|l|}
\hline Bone & $\begin{array}{l}\text { Cadaver 1 } \\
\text { Mean (SD) }\end{array}$ & $\begin{array}{l}\text { Cadaver 2 } \\
\text { Mean (SD) }\end{array}$ & $\begin{array}{l}\text { Cadaver 3 } \\
\text { Mean (SD) }\end{array}$ & $\begin{array}{l}\text { Cadaver 4 } \\
\text { Mean (SD) }\end{array}$ & $\begin{array}{l}\text { Cadaver 5 } \\
\text { Mean (SD) }\end{array}$ \\
\hline T1 & $7.37(0.06)$ & $7.53(0.15)$ & $5.20(0.26)$ & $9.60(0.1)$ & $9.00(0.00)$ \\
\hline T2 & $4.47(0.29)$ & $6.53(0.21)$ & $4.50(0.35)$ & $6.03(0.21)$ & $6.87(0.06)$ \\
\hline T3 & $3.83(0.71)$ & $4.53(0.15)$ & $3.83(0.15)$ & $4.50(0.1)$ & $5.70(0.10)$ \\
\hline T4 & $2.93(0.15)$ & $4.30(0.46)$ & $3.77(0.15)$ & $4.10(0.2)$ & $5.53(0.06)$ \\
\hline T5 & $2.77(0.25)$ & $3.60(0.17)$ & $3.60(0.26)$ & $4.80(0.36)$ & $7.03(0.12)$ \\
\hline T6 & $2.23(0.21)$ & $5.37(0.59)$ & $4.30(0.10)$ & $3.57(0.90)$ & $7.10(0.20)$ \\
\hline T7 & $3.97(0.15)$ & $5.63(0.21)$ & $4.63(0.06)$ & $7.43(0.15)$ & $7.43(0.25)$ \\
\hline T8 & $4.53(0.38)$ & $6.03(0.15)$ & $4.20(0.20)$ & $7.37(0.74)$ & $7.87(0.31)$ \\
\hline T9 & $5.60(0.20)$ & $5.90(0.10)$ & $4.07(0.12)$ & $6.73(0.06)$ & $7.90(0.10)$ \\
\hline T10 & $5.90(0.00)$ & $6.13(0.29)$ & $5.23(0.29)$ & $8.33(0.12)$ & $11.33(0.59)$ \\
\hline T11 & $6.40(0.10)$ & $7.07(0.15)$ & $8.13(0.15)$ & $10.20(0.00)$ & $10.67(0.15)$ \\
\hline T12 & $9.10(0.20)$ & $7.63(0.15)$ & $7.33(0.15)$ & $10.57(0.15)$ & $7.90(0.70)$ \\
\hline
\end{tabular}

Table 2: Relationship between CV and transverse diameter of pedicle per cadaver

\begin{tabular}{|l|l|l|}
\hline Cadaver & Coefficient & P-value \\
\hline One & -1.532 & \\
\hline Two & -1.394 & 0.037 \\
\hline Three & -0.641 & 0.063 \\
\hline Four & -1.685 & 0.158 \\
\hline Five & 0.307 & 0.048 \\
\hline
\end{tabular}

\section{DISCUSSION}

The most accurate method of determining pedicle diameter in human cadaveric spine specimens is direct manual measurement with Vernier calipers (Scoles et al, 1988). Panjabi et al (1991) used the 3D morphometer which gave larger pedicle measurements than those demonstrated in manual and computer tomography bringing to question the validity of the measurements. Computed tomography measurements are influenced by the position of the axial cut made which can be variable. To allay this problem authors have used 3D reconstruction or picked the best image that projects the pedicles in full (Kim et al, 2009). The authors of the current study were concerned that the size of the pedicle influenced the accuracy of the measurements. The reliability of this method, to the authors' best knowledge, has not been documented.
The various specimens were not homogeneous since specimen five possessed relatively larger specimens per level. In-spite of this, the current study confirmed the findings of previous authors that demonstrated that the widest thoracic pedicles are located at the cranial and caudal ends of the thoracic spine, while the mid-thoracic area houses the narrowest pedicles(Berry et al, 1987; Zindrick et al, 1987; Krag et al, 1988; Hou et al, 1993; Heller et al, 1999; Datir and Mitra 2004; Christodoulou et al, 2005; Liau et al, 2006; Choi et al, 2009; Kim et al, 2009; Kretzer et al, 2011; Roop et al, 2011; Bunmaprasert et al, 2014; Yu et al, 2014; Yu et al, 2015 ).

The variance was generally larger in the smaller pedicles. This error is systematic and may be observer-related rather than a weakness of the digital caliper itself; suggesting that the smaller 
pedicle measurement is harder to replicate on repeat measurement. It is unlikely to have arisen because of fatigue or loss of concentration because the number of specimens was limited to five.

The number of specimens was small in this study raising the issue of generalizability of the findings. This needed to be balanced against the possibility of fatigue which potentially causes errors in measurement. The current study demonstrates the negative linear relationship between the coefficient of variation and pedicle diameter in the narrower pedicles. The threshold below which this effect occurs is undetermined. There is also no other known tool to the authors knowledge that could make the readings more accurate. It only suffices for investigators to exercise more caution during measurements of the smaller pedicles. The authors are not able to recommend the exact methodology of this caution; presenting an avenue for further study.

In conclusion, the results demonstrate that variations in measurements tend to increase when the pedicle being measured is narrow and this error is not random. Therefore, Vernier caliper measurements tend to be less reliable as the thoracic pedicle transverse diameter decreases. The mid-thoracic spine region houses the narrowest pedicles and therefore caution needs to be exercised when measuring the transverse diameter with Vernier calipers in this area. Alternative nouveau methods need to be considered.

ACKNOWLEDGEMENTS: This study was carried out at the National Museum of Kenya, Osteology Section. The authors are thankful to Dr Ogeto Mwebi and the Osteology Section staff for their assistance. Investigational and editorial input by Ms Damaris Lagat; and statistical advice from Mr Henry Mwangi are highly appreciated. We are grateful to Moi University and Moi Teaching \& Referral Hospital for providing institutional ethical approval for the conduct of this study.

\section{REFERENCES}

1. Berry JL, Moran JM, Berg WS, Steffee AD.1987. A morphometric study of human lumbar and selected thoracic vertebrae. Spine, 12(4):362-367.

2. Bunmaprasert T, Roobsoong A, Pongmanee S, Khunsree S, Laowatthanaphong S. 2014. Safety entry point, size and direction for placement of thoracic pedicle screw--a cadaveric study. Journal of the Medical Association of Thailand, 1;97(12):1344-51.

3. Choi YS, Kim YJ, Yi HJ. 2009. Pedicle morphometry for thoracic screw fixation in ethnic koreans: radiological assessment using computed tomographic myelography. Journal of Korean Neurosurgical Society, Oct; 46(4):317-21.

4. Christodoulou AG, Apostolou T, Ploumis A, Terzidis I, Hantzokos I, Pournaras J. 2005. Pedicle dimensions of the thoracic and lumbar vertebrae in the Greek population. Clinical Anatomy, 1;18(6):404-8.

5. Datir SP and Mitra SR. 2004. Morphometric study of the thoracic vertebral pedicle in an Indian population. Spine,4;29(11): 1174-1181

6. Gangadhara. 2013. Determination of transpedicular screw parameters with the help of pedicle morphometry of thoracic vertebrae for safe transpedicular screw fixation - a cadaveric study. Journal of Evolution of Medical and Dental Sciences, 36(2): 6807-6815

7. Heller JG, Shuster JK, Hutton WC. 1999. Pedicle and transverse process screws of the upper thoracic spine: biomechanical comparison of loads to failure. Spine, 1;24(7):654-8.

8. Hou S, Hu R, Shi Y. 1993. Pedicle morphology of the lower thoracic and lumbar spine in a Chinese population. Spine, $1 ; 18(13): 1850-5$.

9. Kim JH, Choi GM, Chang IB, Ahn SK, Song JH, Choi HC.2009. Pedicular and extrapedicular morphometric analysis in the Korean population: computed tomographic assessment relevance to pedicle and extrapedicle screw fixation in the thoracic spine. J Korean Neurosurg Soc, 46 (3):181-8

10. Krag MH, Weaver DL, Beynnon BD, Haugh LD. 1988. Morphometry of the thoracic and lumbar spine related to transpedicular screw placement for surgical spinal fixation. Spine, Jan 1;13(1):27-32.

11. Kretzer RM, Chaput C, Sciubba DM, Garonzik IM, Jallo GI, McAffee PC, et al. 2011. A computed tomography-based morphometric study of thoracic pedicle anatomy in a random United States trauma population. J Neurosurg Spine, 14: 235-243 
12. Liau KM, Yusof MI, Abdullah MS, Abdullah S, Yusof AH. 2006. Computed tomographic morphometry of thoracic pedicles: safety margin of transpedicular screw fixation in Malaysian Malay population. Spine, 31(16):45-50

13. McLain RF, Ferrara L, Kabins M. 2002. Pedicle morphometry in the upper thoracic spine:limits to safe screw placement in older patients.Spine, $15 ; 27(22): 2467-2471$

14. Panjabi MM, Takata K, Goel V, Federico D, Oxland T, Duranceau J, Krag M. 1991. Thoracic Human Vertebrae Quantitative Three-Dimensional Anatomy. Spine, 1;16 (8):888-901.

15. Roop S, Srivastva SK, Prasath CS, Rohilla RK, Siwach R, Magu NK. 2011. Morphometric Measurements of Cadaveric Thoracic Spine in Indian Population and Its Clinical Applications. Asian Spine Journal, 5 (1): 2034

16. Scoles PV, Linton AE, Latimer B, Levy ME, Digiovanni BF. 1988. Vertebral body and posterior element morphology: the normal spine in middle life. Spine, 1;13(10):1082-6.

17. Yu CC, Bajwa NS, Toy JO, Ahn UM, Ahn NU. 2014. Pedicle morphometry of upper thoracic vertebrae: an anatomic study of 503 cadaveric specimens. Spine,15;39(20):E1201-9.

18. Yu CC, Yuh RT, Bajwa NS, Toy JO, Ahn UM, Ahn NU. 2015. Lower thoracic pedicle morphometry: male, taller, and heavier specimens have bigger pedicles. Spine, 5;40(6):E323-31.

19. Zindrick MR, Wiltse LL, Doornik A, Widell EH, Knight GW, Patwardhan AG, Thomas JC, Rothman SL, Fields BT. 1987. Analysis of the morphometric characteristics of the thoracic and lumbar pedicles. Spine, $1 ; 12(2): 160-6$. 